\title{
KEBUTUHAN PMIK BERDASARKAN ANALISA BEBAN KERJA PADA BAGIAN ASSEMBLING RAWAT INAP RUMAH SAKIT X BANDUNG
}

\author{
Tina Dwiasih ${ }^{1}$, Nurul Amalya ${ }^{2}$, Yuyun Yunengsih ${ }^{3}$ \\ Politeknik Piksi Ganesha ${ }^{1,2,3}$ \\ piksi.tinadwiasih.18303079@gmail.com ${ }^{1}$, nurulamalya23@gmail.com², \\ yoen1903@gmail.com ${ }^{3}$
}

Received: 17-08-2021

Revised : 20-10-2021

Accepted: 24-10-2021

\begin{abstract}
Abstrak
Latar Belakang: Rumah sakit X merupakan salah satu rumah sakit swasta tipe $\mathrm{c}$ di daerah Cileunyi, Bandung Jawa Barat. Di rumah sakit $\mathrm{X}$ terdapat 38 perekam medis unit rekam medis 3 diantaranya bertugas di bagian assembling. Berdasarkan jumlah pasien rawat inap yang cenderung meningkat setiap bulannya dan adanya faktor lain yaitu tugas rangkap diluar tugas pokok sehingga beban kerja petugas assembling dalam pengolahan data pasien meningkat. Untuk itu diperlukan keseimbangan antara beban kerja dengan jumlah petugas assembling.
\end{abstract}

Tujuan: Penelitian ini bertujuan untuk mengetahui kebutuhan PMIK berdasarkan analisa beban kerja pada bagian assembling rawat inap.

Metode: Jenis penelitian ini adalah penelitian deskriptif dengan metode wawancara dan observasi melalui pendekatan cross sectional. Populasi dalam penelitian ini adalah kepala rekam medis dan petugas unit rekam medis bagian assembling.

Hasil: Berdasarkan hasil penelitian perhitungan kebutuhan tenaga kerja berdasarkan beban kerja petugas assembling rawat inap RS X menggunaka metode ABK Kes, didapatkan jumlah petugas assembling dengan standar beban kerja sebanyak 59.600 menit per 6 bulan dibutuhkan sebanyak 4 petugas perekam medis.

Kesimpulan: Jumlah perekam medis tersebut belum sesuai dengan jumlah perekam medis sekarang yaitu 3 perekam medis, maka dari itu dibutukan 1 perekam medis tambahan di bagian assembling agar pelaksanaan rekam medis bisa berjalan dengan baik.

Kata kunci: rumah sakit; assembling; beban kerja; ABKKes; rekam medis.

\begin{abstract}
Background: Hospital $X$ is a type c private hospital in the Cileunyi area, Bandung, West Java. In hospital $X$, there are 38 medical recorders, 3 of which are in thedepartment assembly. Based on the number of inpatients which tend to increase every month and the existence of other factors,
\end{abstract}




namely dual tasks outside the main task so that the workload
of assembling officers in processing patient data increases.
This requires a balance between the workload and the
number of assembling officers.
Objective: This study aims to determine the need for PMIK
based on workload analysis in the assembly
inpatientdepartment.
Methods: This type of research is a descriptive study with
interview and observation methods through aapproach
cross sectional. The population in this study were the head
of the medical record and the medical record unit officer in
thesection assembling.
Results: Based on the results of the study, the calculation of
labor requirements based on the workload of inpatient
assembling officers at X Hospital using the ABK Kes
method, it was found that the number of assembling officers
with a standard workload of 59,600 minutes per 6 months
required 4 medical recorders.
Conclusion: The number of medical recorders is not in
accordance with the current number of medical recorders,
namely 3 medical recorders, therefore 1 additional medical
recorder is needed in the assembly section so that the
implementation of medical records can run well.
Keywords: hospital; assembling; workload; ABK-Kes;
medical record.
Email : piksi.tinadwiasih.18303079@gmail.com
cor

\section{PENDAHULUAN}

Fasilitas pelayanan kesehatan adalah suatu alat atau tempat yang digunakan untuk upaya pelayanan kesehatan yang di upayakan oleh pemerintah daerah maupun masyarakat. Di indonesia sendiri banyak sekali pelayanan kesehatan yang tersedia, contohnya rumah sakit, posyandu, puskesmas, klinik dokter, balai kesehatan dan masih banyak lagi. Diantara pelayanan kesehatan diatas, rumah sakit adalah fasyankes yang memeberikan pelayanan paling kompleks. Menurut World Health Organization, Rumah sakit adalah bagian integral dari suatu organisasi sosial dan kesehatan dengan fungsi menyediakan pelayanan paripurna (komprehensif), penyembuh penyakit (kuratif) dan pencegahan penyakit (preventif) kepada masyarakat (Budi, 2011).

Dalam upaya menjalankan tugas nya, rumah sakit membutuhkan unit-unit agar bisa membantu dalam menjalankan pelayanan kesehatan, salah satunya adalah unit rekam medis. Menurut Peraturan Menteri Kesehatan (Permenkes RI, 2008), Rekam medis adalah berkas yang berisikan catatan dan dokumen tentang identitas pasien, pemeriksaan, pengobatan, tindakan, dan pelayanan lain yang telah diberikan kepada pasien (Permenkes, 2008). Sebagai salah satu unit terpenting di rumah sakit, unit rekam medis berperan sebagai salah satu ukuran kepuasan pasien dalam menerima pelayanan kesehatan. Begitu pula jumlah petugas rekam medis pun sangatlah berpengaruh bagi rumah sakit, apabila dalam rumah sakit terjadi keterlambatan dalam melayani pasien karena kurangnya petugas rekam medis maka akan mempengaruhi mutu dan kualitas rumah sakit tersebut. 
Ruang lingkup dari unit rekam medis yaitu diawali dari mulai penerimaan pasien sampai dengan pengumpulan data, pengolahan data juga sampai penyajian data informasi kesehatan. Proses pengolahan berkas rekam medis dilakukan oleh unit khusus yaitu unit rekam medis bagian assembling karena diperlukan adanya ketelitian dan kemampuan yang baik dalam mengolah data pasien, agar data tersebut bisa disajikan dengan baik dan benar untuk bisa dijadikan sumber informasi bagi rumah sakit, administrator dan manajemen pada sarana Kesehatan dan instansi lain yang berkepentingan berdasarkan ilmu pengetahuan teknologi rekam medis (Komisi Akreditasi Rumah Sakit, 2016)

Agar terlaksananya pelayanan rekam medis yang berkualitas sesuai dengan beban kerja yang ada, serta tercapainya tujuannya yaitu ke efisiensian dan kesejahteraan yang berkaitan dengan produktifitas dan kepuasan kerja terutama disuatu rumah sakit, untuk mencapai tujuan tersebut haruslah memperhatikan pada aspek ergonominya dimana aspek ini dapat berpengaruh pada kenyamanan kerja petugas (Tengah, Tahun, \& Alifah, 2014).

Selain asepek ergonomi, hal yang harus diperhatikan agar pelayanan rekam medis dapat berjalan baik adalah kualifikasi dan kualitas perekam medis itu sendiri. Dalam penelitian oleh jacobs (Jacobis, Kojo, \& Wenas, 2017) disebutkan bahwa karakteristik dan kualitas individu secara parsial berpengaruh positif terhadap kinerja dan kualitas kerja pegawai. Dalam PERMEKES No.55 tahun 2013 pun dinyatakan bahwa kompetensi perekam medis ialah perekam medis yang telah terbukti kompeten dengan mempunyai surat tanda teregistrasi atau STR. Surat tanda registrasi perekam medis adalah bukti tertulis yang diberikan oleh Pemerintah kepada perekam medis yang telah memiliki sertifikat kompetensi sesuai ketentuan peraturan perundang-undangan (Permenkes RI no.55, 2013).

Menyadari hal tersebut maka jumlah petugas harus disesuaikan dengan jumlah beban kerja tersedia sehingga produktifitas para petugas bisa lebih optimal. Jika jumlah tenaga kerja sedikit, sedangkan beban kerja semakin meningkatkan terjadi kelelahan kerja, produktifitas kerja menurun dan akan mempengaruhi mutu pelayanan rumah sakit, demikian juga sebaliknya jika jumlah petugas lebih banyak beban kerja, maka banyak pula waktu yang tersisa sehingga pekerjaan menjadi kurang efektif (Imanti \& Setyowati, 2015).

Menurut buku Rekam Medis karya Dr. Rano Indradi S, M.Kes. teori tugas dan fungsi petugas assembling yaitu (a) merakit kembali formulir-formulir DRM Rawat Jalan, Rawat Inap, Gawat Darurat menjadi urut/runtut sesuai dengan kronologi penyakit pasien yang bersangkutan, (b) meniliti kelengkapan data yang tercatat didalam formulir rekam medis sesuai dengan kasus penyakitnya, (c) mengendalikan Dokumen Rekam Medis yang dikembalikan ke unit pencatat data karena isinya tidak lengkap, (d) mengendalikan penggunaan nomor rekam medis dan (e) mendistribusikan dan mengendalikan penggunaan formulir rekam medis (Indradi, 2017).

Rumah Sakit X Bandung adalah rumah sakit tipe C mempunyai kapasitas tempat tidur sebanyak 207 dan jumlah tenaga unit rekam medis bagian assembling yaitu 3 petugas dengan hari kerja 6 hari yaitu Senin sampai Jumat dengan jam datang pukul 08.00 sampai dengan 16.00, hari sabtu pukul 08.00 sampai dengan 12.00. Dari hasil observasi awal kami di RS x, kami menemukan adanya peningkatan jumlah pasien rawat inap setiap bulannya serta tugas rangkap di bagian assembling yang bukan termasuk SOP. Hal ini tentu mempengaruhi keseimbangan antara beban kerja assembling dan jumlah perekam medis di bagian assembling. Untuk itu kebutuhan tenaga kerja petugas assembling di rumah sakit X memerlukan suatu perencanaan dan pengembangan dengan menghitung kebutuhan tenaga kerja berdasarkan beban kerja petugas agar didapatkan tenaga yang berkualitas sesuai dengan kebutuhan. Maka dari itu tujuan dibuatnya jurnal ini adalah untuk menganalisa kebutuhan beban kerja perekam medis di bagian assembling.

Tujuan dari penelitian ini adalah untuk menganalisa kebutuhan beban kerja perekam medis di bagian assembling agar tidak memepengarui tingkat efisiensi dan produktivitas PMIK, juga mengurangi tingkat kelelahan pekerja yang dapat mempengaruhi produktivitas dan mutu pelayanan kesehatan rumah sakit. 


\section{METODE PENELITIAN}

Penelitian ini adalah jenis penelitian deskriptif yaitu penelitian yang dilakukan sekumpulan objek yang biasanya bertujuan untuk menggambarkan suatu fenomena dalam populasi tertentu, penelitian ini juga menggunakan pendekatan cross sectional dimana data yang bersangkutan dengan variable bebas atau variable resiko akan dikumpulkan dalam waktu yang sama (Notoamodjo Soekidjo, 2018).

Cara pengumpulan data disini adalah dengan cara wawancara dan observasi. Di dalam buku Metedologi Penelitian Kesehatan disebutkan bahwa Wawancara adalah proses komunikasi atau interaksi untuk mengumpulkan informasi dengan cara tanya jawab antara peneliti dengan informan atau subjek penelitian (Emzir, 2010). Sedangkan observasi merupakan kegiatan dengan menggunakan pancaindera, bisa penglihatan, penciuman, pendengaran, untuk memperoleh informasi yang diperlukan untuk menjawab masalah penelitian (Masthuroh \& Anggita, 2018).

Lokasi penelitian pun bertempat di Rumah Sakit X Daerah Bandung Jawa Barat dengan populasi penelitian adalah 3 orang perekam medis bagian assembling dan kepala rekam medis. Analisa perhitungan beban kerja adalah dengan metode ABK Kes (angka kebutuhan beban kerja kesehatan) yaitu metode kebutuhan SDMIK berdasarkan pada beban kerja yang dilaksanakan oleh setiap jenis SDMIK pada tiap fasilitas pelayanan kesehatan sesuai dengan tugas pokok dan tugas penunjang serta fungsinya (Tim Pusrengun SDM Kesehatan PPSDM Kes RI Konsultan: Pardjono, SKM, 2017).

\section{HASIL DAN PEMBAHASAN}

\section{A. Hasil Penelitian}

Hasil akhir perhitungan kebutuhan PMIK di RS X terdapat pada tabel 4 yakni perhitungan kebutuhan SDMK per fasyankes. Adapun tabel yang memperlihatkan proses proses perhitungan dari awal sampai mendapatkan hasil yang riil dari penelitian ini. Disediakan juga tabel kualifikasi kapasitas perekam medis bagian assembling di RS X.

Tabel 1. Kapasitas Kerja Perekam Medis Bagian Assembling Rawat Inap

\begin{tabular}{ccccc}
\hline \multirow{2}{*}{ Petugas } & \multirow{2}{*}{ Umur } & \multicolumn{2}{c}{ Karakteristik petugas } & \multirow{2}{*}{ Lama kerja } \\
\cline { 3 - 5 } & & Jenis kelamin & Pendidikan & \\
\hline A & 26 & Perempuan & D3-rekam medis & 1 tahun \\
\hline B & 26 & Perempuan & D4-rekam medis & 2 tahun \\
\hline C & 24 & Perempuan & D3-rekam medis & 3 tahun \\
\hline
\end{tabular}

Sumber: data primer rumah sakit

Tabel 2 Waktu Kerja Tersedia Perekam Medis Assembling

\begin{tabular}{ccccccc}
\hline No & Kode & Komponen & Keterangan & Rumus & Jumlah & Satuan \\
\hline & A & B & \multicolumn{1}{c}{ C } & D & E & F \\
\hline 1 & & A & $\begin{array}{l}\text { 5 Hari Kerja / } \\
\text { Minggu }\end{array}$ & 26 Minggu & 130 & $\begin{array}{l}\text { Hari / 6 } \\
\text { bulan }\end{array}$ \\
\cline { 3 - 6 } 2 & & $\begin{array}{l}\text { 6 Hari Kerja / } \\
\text { Minggu }\end{array}$ & 26 Minggu & 156 & $\begin{array}{l}\text { Hari / 6 } \\
\text { bulan }\end{array}$ \\
\hline 3 & B & Cuti Pegawai & $\begin{array}{l}\text { Peraturan } \\
\text { Pegawai }\end{array}$ & - & 12 & $\begin{array}{l}\text { Hari / 6 } \\
\text { bulan }\end{array}$ \\
\hline
\end{tabular}




\begin{tabular}{|c|c|c|c|c|c|c|}
\hline 4 & $\mathrm{C}$ & $\begin{array}{l}\text { Libur } \\
\text { Nasional }\end{array}$ & $\begin{array}{l}6 \text { bulan } \\
\text { (Kalender) }\end{array}$ & - & 15 & $\begin{array}{l}\text { Hari / } 6 \\
\text { bulan }\end{array}$ \\
\hline 5 & $\mathrm{D}$ & $\begin{array}{l}\text { Mengikuti } \\
\text { Pelatihan }\end{array}$ & $\begin{array}{l}\text { Rata - rata } 6 \\
\text { bulan }\end{array}$ & - & 0 & $\begin{array}{l}\text { Hari / } 6 \\
\text { bulan }\end{array}$ \\
\hline 6 & $\mathrm{E}$ & $\begin{array}{l}\text { Absen (Sakit, } \\
\text { Cuti Lahiran) }\end{array}$ & $\begin{array}{l}\text { Rata - rata dalam } \\
6 \text { bulan }\end{array}$ & - & 64 & $\begin{array}{l}\text { Hari / } 6 \\
\text { bulan }\end{array}$ \\
\hline 7 & $\mathrm{~F}$ & $\begin{array}{l}\text { Waktu Kerja } \\
\text { (dalam } 1 \\
\text { minggu) }\end{array}$ & $\begin{array}{l}\text { Kepres No. } \\
68 / 1995\end{array}$ & - & 39 & $\begin{array}{l}\text { Jam / } \\
\text { Minggu }\end{array}$ \\
\hline 8 & G & $\begin{array}{l}\text { Jam Kerja } \\
\text { Efektif (JKE) }\end{array}$ & $\begin{array}{l}\text { Permenkes PAN - } \\
\text { RB 26/2011 }\end{array}$ & $75 \%$ X 39 Jam & 29 & $\begin{array}{l}\text { Jam / } \\
\text { Minggu }\end{array}$ \\
\hline 9 & \multirow{2}{*}{ WK } & \multirow{2}{*}{$\begin{array}{l}\text { Waktu Kerja } \\
\text { (dalam } 1 \\
\text { hari) }\end{array}$} & $\begin{array}{l}5 \text { Hari Kerja / } \\
\text { Minggu }\end{array}$ & $\mathrm{E} 8 / 5$ & 5.85 & $\begin{array}{l}\text { Jam / } \\
\text { Hari }\end{array}$ \\
\hline 10 & & & $\begin{array}{l}6 \text { Hari Kerja / } \\
\text { Minggu }\end{array}$ & $\mathrm{E} 8 / 6$ & 4.875 & $\begin{array}{l}\text { Jam / } \\
\text { Hari }\end{array}$ \\
\hline 11 & \multirow{4}{*}{ - WKT } & \multirow{2}{*}{$\begin{array}{l}\text { Waktu Kerja } \\
\text { Tersedia } \\
\text { (hari) }\end{array}$} & $\begin{array}{l}5 \text { Hari Kerja / } \\
\text { Minggu }\end{array}$ & $\begin{array}{c}\mathrm{E} 1-(\mathrm{E} 3+\mathrm{E} 4+\mathrm{E} 5 \\
+\mathrm{E} 6)\end{array}$ & 39 & $\begin{array}{l}\text { Hari / } 6 \\
\text { bulan }\end{array}$ \\
\hline 12 & & & $\begin{array}{l}6 \text { Hari Kerja / } \\
\text { Minggu }\end{array}$ & $\begin{array}{c}\mathrm{E} 2-(\mathrm{E} 3+\mathrm{E} 4+\mathrm{E} 5 \\
+\mathrm{E} 6)\end{array}$ & 65 & $\begin{array}{l}\text { Hari / } 6 \\
\text { bulan }\end{array}$ \\
\hline 13 & & \multirow{2}{*}{$\begin{array}{l}\text { Waktu Kerja } \\
\text { Tersedia } \\
\text { (Jam) }\end{array}$} & $\begin{array}{l}5 \text { Hari Kerja / } \\
\text { Minggu }\end{array}$ & $\begin{array}{c}\mathrm{E} 1-(\mathrm{E} 3+\mathrm{E} 4+\mathrm{E} 5 \\
+\mathrm{E} 6) \mathrm{X} \mathrm{E} 9\end{array}$ & 228 & $\begin{array}{l}\text { Jam / } 6 \\
\text { bulan }\end{array}$ \\
\hline 14 & & & $\begin{array}{l}6 \text { Hari Kerja / } \\
\text { Minggu }\end{array}$ & $\begin{array}{c}\mathrm{E} 2-(\mathrm{E} 7+\mathrm{E} 8+\mathrm{E} 9 \\
+\mathrm{E} 10) \mathrm{X} \mathrm{E} 10\end{array}$ & 316.875 & $\begin{array}{l}\text { Jam / } 6 \\
\text { bulan }\end{array}$ \\
\hline \multicolumn{5}{|c|}{ Waktu Kerja Tersedia ( WKT) ...... Dibulatkan (dalam jam) } & 317 & $\begin{array}{l}\text { Jam / } 6 \\
\text { bulan }\end{array}$ \\
\hline \multicolumn{5}{|c|}{ Waktu Kerja Tersedia ( WKT) ...... Dibulatkan (dalam menit) } & 19020 & $\begin{array}{l}\text { Menit / } \\
6 \text { bulan }\end{array}$ \\
\hline
\end{tabular}

Tabel 3 Komponen Kerja dan Hasil Hitung SBK Perekam Medis Assembling (Tugas pokok)

\begin{tabular}{|c|c|c|c|c|c|c|}
\hline No & $\begin{array}{l}\text { Jenis } \\
\text { Tugas }\end{array}$ & Komponen Beban Kerja (Kegiatan) & $\begin{array}{l}\text { Norma } \\
\text { waktu }\end{array}$ & Satuan & $\begin{array}{l}\text { WKT } \\
\text { (Menit) }\end{array}$ & SBK \\
\hline \multirow[t]{6}{*}{1} & $\begin{array}{l}\text { Tugas } \\
\text { Pokok }\end{array}$ & $\begin{array}{l}\text { Menerima, mengecek pengembalian } \\
\text { berkas rekam medis dari ruang } \\
\text { perawatan dan membuat memo }\end{array}$ & 2 & $\begin{array}{l}\text { Menit / } \\
\text { DRM }\end{array}$ & 19020 & 9510 \\
\hline & & $\begin{array}{l}\text { Melakukan assembling berkas rekam } \\
\text { medis sesuai penurunan terlama }\end{array}$ & 5 & $\begin{array}{c}\text { Menit / } \\
\text { DRM }\end{array}$ & 19020 & 3804 \\
\hline & & $\begin{array}{l}\text { Melakukan pengecekan kelengkapan } \\
\text { semua formulir }\end{array}$ & 3 & $\begin{array}{l}\text { Menit / } \\
\text { DRM }\end{array}$ & 19020 & 6340 \\
\hline & & $\begin{array}{l}\text { Merapihkan dan membersihkan rekam } \\
\text { medis yang kotor }\end{array}$ & 3 & $\begin{array}{l}\text { Menit / } \\
\text { DRM }\end{array}$ & 19020 & 6340 \\
\hline & & Menulis di buku pengembalian & 2 & $\begin{array}{l}\text { Menit / } \\
\text { DRM }\end{array}$ & 19020 & 9510 \\
\hline & & $\begin{array}{l}\text { Melakukan analisis ketidaklengkapan } \\
\text { rekammedis }\end{array}$ & 5 & $\begin{array}{c}\text { Menit / } \\
\text { DRM }\end{array}$ & 19020 & 3804 \\
\hline
\end{tabular}

Tabel 4 Komponen Kerja dan Hasil Hitung SBK Perekam Medis Assembling (Tugas Penunjang) 


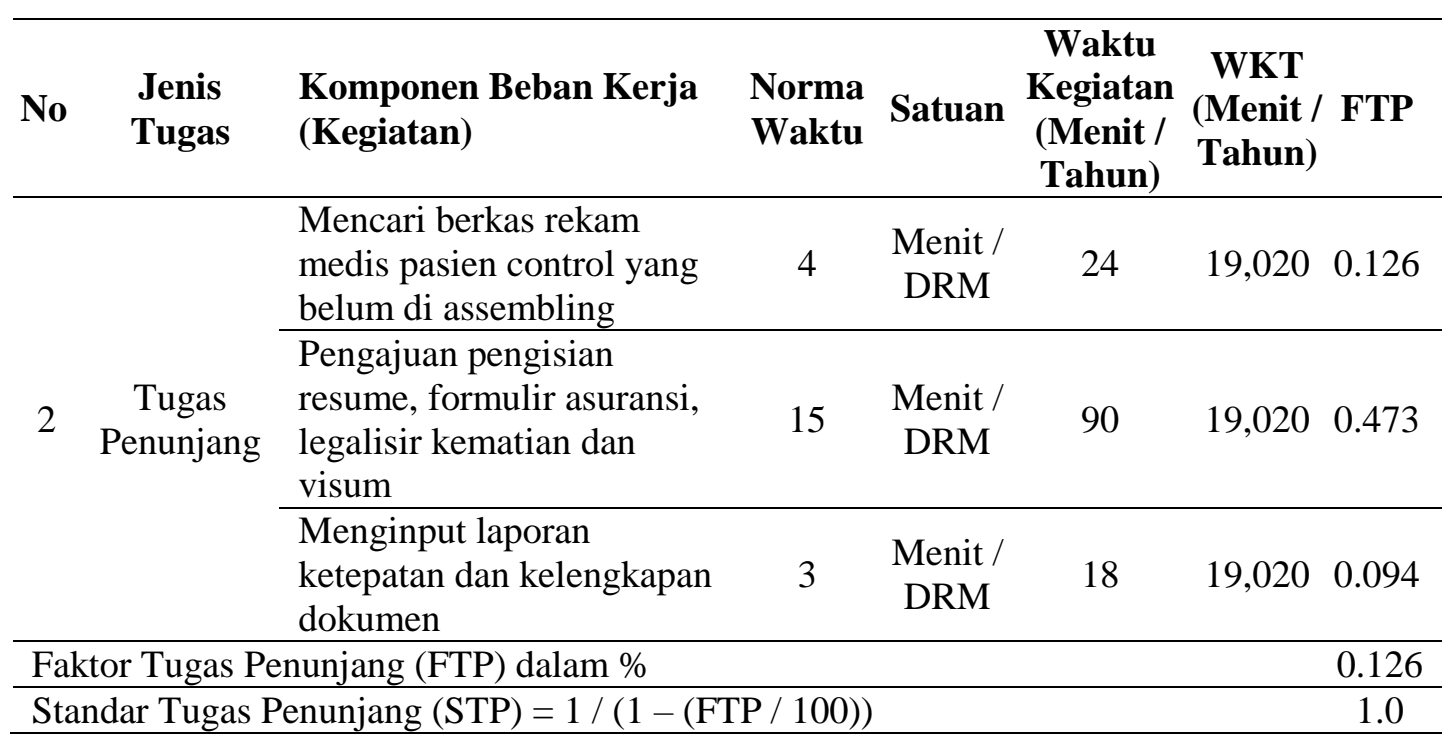

Tabel 4 Perhitungan Kebutuhan SDMK Per-fasyankes

\begin{tabular}{|c|c|c|c|c|c|}
\hline No & $\begin{array}{l}\text { Jenis } \\
\text { Tugas }\end{array}$ & Komponen Beban Kerja (Kegiatan) & $\begin{array}{c}\text { Capaian } \\
(6 \text { Bln })\end{array}$ & SBK & $\begin{array}{l}\text { Kebutuhan } \\
\text { SDMK }\end{array}$ \\
\hline \multirow{6}{*}{1} & \multirow{6}{*}{$\begin{array}{l}\text { Tugas } \\
\text { Pokok }\end{array}$} & $\begin{array}{l}\text { Menerima, mengecek pengembalian } \\
\text { berkas rekam medis dari ruang perawatan } \\
\text { dan membuat memo }\end{array}$ & \multirow{6}{*}{3505} & 9510 & 0.369 \\
\hline & & $\begin{array}{l}\text { Melakukan assembling berkas rekam } \\
\text { medis sesuai penurunan terlama }\end{array}$ & & 3804 & 0.922 \\
\hline & & $\begin{array}{l}\text { Melakukan pengecekan kelengkapan } \\
\text { semua formulir }\end{array}$ & & 6340 & 0.553 \\
\hline & & $\begin{array}{l}\text { Merapihkan dan membersihkan rekam } \\
\text { medis yang kotor }\end{array}$ & & 6340 & 0.553 \\
\hline & & Menulis di buku pengembalian & & 9510 & 0.369 \\
\hline & & $\begin{array}{l}\text { Melakukan analisis ketidaklengkapan } \\
\text { rekammedis }\end{array}$ & & 3804 & 0.922 \\
\hline & \multicolumn{4}{|c|}{ Jumlah Kebutuhan Tenaga (JKT) PMIK Assembling } & 4 \\
\hline & \multicolumn{4}{|c|}{$\begin{array}{ll}\text { Tugas } & \text { Standar Tugas Penunjang (Penghitungan Table 3.2) } \\
\text { Penunjang } & \end{array}$} & 1.0 \\
\hline & \multicolumn{4}{|c|}{ Total Kebutuhan SDMK (PMIK Assembling) = JKT X STP } & 3.69 \\
\hline & \multicolumn{4}{|c|}{ Pembulatan } & 4 \\
\hline & \multicolumn{4}{|c|}{ Karena sudah ada 3 PMIK } & 1 \\
\hline
\end{tabular}

Sumber: data primer rumah sakit

Berdasarkan hasil pada table 4, perhitungan di atas di dapatkan hasil bahwa total kebutuhan SDMK (PMIK Assembling) di RS X ialah 3,69. Hasil tersebut dibulatkan, maka hasil perhitungan ialah 4 SDMK. Di karenakan di RS X sudah tersedia SDMK sebanyak 3 PMIK bagian assembling, maka berdasarkan perhitungan dibutuhkan 1 PMIK tambahan di bagian assemblig agar proses pengolahan data dapat berjalan dengan sesuai.

\section{B. Pembahasan}

Menurut hasil pengamatan yang dilakukan, tugas pokok dan fungsi petugas assembling yang di terapkan di rumah sakit $\mathrm{X}$ Bandung sudah sesuai dengan teori yaitu yaitu menerima, mengecek, juga membuat memo pengembalian berkas rekam medis dari 
bangsal, melakukan assembling sesuai urutan, pengecekan kelengkapan formulir berkas rekam medis, merapihkan dan membersihkan berkas rekam medis, dan menganalisa ketidak lengkapan berkas. Tidak hanya itu, petugas assembling juga mempunyai tugas rangkap yang meliputi menginput laporan ketepatan dan kelengkapan dokumen, mencari dan memilah berkas px control, juga melakukan pengajuan pengajuan permitaan pasien atau keluarga pasien, seperti pengajuan formulir asuransi, sertifikat kematian, visum, menjadi petugas pendaftaran rawat jalan/gawat darurat dan lainnya yang bukan merupakan tugas pokok petugas assembling.

Menurut hasil wawancara dengan salah satu petugas yang bertanggung jawab di bagian assembling, kendala yang terjadi adalah rangkap tugas. Yang mana setiap petugas bagian assembling mempunyai tugas rangkap tersendiri, hal tersebut berdampak pada kualitas dan mutu pekerjaan di assembling, karena bila petugas melakukan pekerjaan di luar tugas pokoknya maka pekerjaan yang menjadi tugas pokok utama di assembling menjadi menumpuk sehingga menambah beban kerja pada keesokan harinya. Dan juga, tidak adanya atau belum adanya pelatihan khusus petugas assembling yang dimaksud untuk memperluas pengetahuan, meningkatkan kinerja dan motivasi yang tinggi untuk menyelesaikan pekerjaanya.

Menurut (Jacobis et al., 2017) karateristik pegawai memepunyai banyak peran dalam kinerja para pekerja sehari hari. Di rumah sakit X terdapat 3 perekam medis bagian assembling. 2 diantaranya merupakan lulusan D3 jurusan rekam medis dan 1 orang merupakan lulusan D4 jurusan rekam medis. Rentan usia perekam medis bagian assembling ialah 24-26 tahun dengan lamakerja perekam medis ini rata-rata 1-3 tahun. Volume rata2 kegiatan petugas assembling perhari ialah 35 DRM perhari serta estimasi pengerjaan per point SOP ialah 2-5 menit per DRM.

Perhitungan kebutuhan perekam medis bagian assembling di RS x dengan menggunakan metode ABK Kes ialah (1) menentukan Fasyankes dan jenis SDMK, fayankes yang diteliti ialah RS X daerah Bandung Jawa Barat denga kelompo SDMK ialah unit rekam medis dengan jenis SDMK perekam medis bagian assembling. (2) menetukan WKT yaitu waktu yang digunkan oleh SDMK untuk melakukan tugas dan kegiatannya dalam kurun waktu tertentu. (3) menetapkan komponen beban kerja (uraian tugas pokok, tugas penunjang atau tugas rangkap) (4) menghitung standar beban kerja yaitu volume/kuantitas pekerjaan dalam waktu tertentu dalam setiap jenis SDMK dengan menggunakan rumus:

\section{$\underline{\text { SBK }=\text { Waktu Kerja Tersedia }(\text { WKT) }}$ Norma Waktu Per Kegiatan Pokok}

(5) menghitung faktor dan standar kegiatan penunjang yaitu proporsi waktu yang digunakan untuk menyelesaikan setiap kegiatan persatuan waktu (hari, minggu, bulan, triwula, semester dll) sedangkan Standar Tugas Penunjang adalah suatu nilai yang merupakan pengali terhadap kebutuhan SDMK tugas pokok. Rumus yang digunakan ialah:

$$
\begin{gathered}
\text { Faktor Tugas Penunjang }(\text { FTP })=(\text { Waktu Kegiatan }):(\text { WKT }) \times 100 \\
\text { dan } \\
\text { Standar Tugas Penunjang }(\text { STP })=1 /(1-(\text { FTP } / 100))
\end{gathered}
$$

Langkah terkahir untuk menghitung kebutuhan pmik ialah (6) menghitung kebutuhan SDMK per institusi dengan menggunakan rumus (Muhaemin, 2017):

Kebutuhan SDMK = Capaian (1 Tahun) X Standar Tugas Penuniang (STP) Standar Beban Kerja (SBK) 
Berdasarkan hasil perhitungan, angka kebutuhan tenaga kerja di rumah sakit $\mathrm{X}$ menggunakan metode ABK Kes ialah 4 orang petugas dengan hari kerja 157 hari per 6 bulan, diketahui beban kerja petugas assembling pada bulan Januari-Juni tahun 2021 adalah sebanyak 3505 pasien atau dokumen. Perhitungan waktu kerja tersedia sesuai rumus dalam teori diketahui jumlah hari kerja dalam 6 bulan yaitu 157 hari, jumlah hari libur nasional dalam 6 bulam adalah 15 hari, jumlah hari cuti tahunan dalam 6 bulan adalah 12 hari, jumlah hari ketidakhadiran kerja dalam 6 bulan adalah 3 hari serta jumlah jam kerja dalam satu minggu adalah 39 jam dengan waktu kerja perhari dari hari Senin-Jumat 7 jam kerja sedangkan hari Sabtu 4 jam kerja. Dari data yang telah diketahui tersebut menghasilkan perhitungan sebesar $381 \mathrm{jam} / 6$ bulan atau 22.800 menit/ 6 bulan dengan waktu kerja efektif 29,25 jam/minggu.

Perhitungan kebutuhan tenaga kerja di atas bertujuan untuk mengetahui jumlah petugas assembling yang diperlukan sesuai beban kerja selama 6 bulan. Dari hasil perhitungan telah diketahui kebutuhan tenaga kerja assembling di tahun 2021 adalah sebanyak 4 orang petugas. Sedangkan di RS X Bandung memiliki 3 orang petugas sehingga di butuhkan 1 petugas tambahan, karena beban kerja petugas assembling di RS X masih belum sesuai.

Selain kurangnya petugas, kendala di bagian assembling adalah masih ditemukannya berkas rekam medis yang belum lengkap dan tidak tepat waktunya pengembalian berkas rekam medis dari ruang perawatan ke bagian assembling. Dari hasil observasi, diketahui ketidaklengkapan dokumen rekam medis terdiri dari tanda tangan, jam dan diagnosa serta sering terjadi keterlambatan pengembalian berkas melebihi waktu yang terlah ditentukan yaitu $1 \times 24$ jam. Hal hal tersebut justru menyebabkan penumpukan nya dokumen dan berdampak pada bertambahnya beban kerja PMIK bagian assembling. Ini pun dibuktikan dalam jurnal Viviene dan Maryani pada tahun 2016 yang menyatakan bahwa salah satu masalah di bagian assembling adalah banyaknya dokumen yang harus diteliti ulang kelengkapannya, hal itu karena petugas harus meneliti dan sekaligus harus merakit DRM (tugas rangkap) yang akan berakibat pada keterlambatan pengkodingan dan pelaporan, juga akan berdampak pada keterlambatan penyediaan DRM bagi pasien kontrol rutin setelah melakukan rawat inap.

\section{KESIMPULAN}

Berdasarkan hasil penelitian maka dapat disimpulan bahwa karakteristik SDM di unit rekam medis rs $\mathrm{x}$ bagian assembling sudah sangat baik, ditinjau dari Pendidikan terkahir perekam medis yang semuanya sudah menjadi diploma yang dimana mereka semua pasti sudah mempunyai STR (Surat Tanda Registrasi) yaitu surat yang bisa menilai bahwa perekam medis tersebut sudah berkompeten. Dari hasil perhitungan dan penelitian peneliti tentang kebutuhan beban kerja mengunakan metode ABK Kes didapatkan hasil bahwa jumlah petugas yang dibutuhkan adalah sebanyak 4 orang. Jumlah tersebut belum sesuai dengan jumlah petugas yang tersedia saat ini yaitu 3 orang. Jadi dibutuhkan 1 orang perekam medis tambahan di bagian assembling. Terdapat banyaknya tugas rangkap yang dilakukan bagian assembling sehinga menyebabkan para petugas tidak fokus pada pekerjaannya dan berdampak pada beban kerja yang menumpuk pada keesokan harinya. Tidak adanya pelatihan seperti pelatihan tentang analisa berkas rekam medis yang merupakan hal penting agar pengetahuan bagi para perekam medis assembling tentang rekam medis dan assembling bisa lebih luas. 


\section{BIBLIOGRAFI}

Permenkes RI no. 5. thn. (2013). Peraturan Menteri Kesehatan Republik Indonesia Nomor 55 Tahun 2013. Journal of Chemical Information and Modeling, 53(9), 1689-1699.

Budi, Savitri Citra. (2011). Manajemen unit kerja rekam medis. Yogyakarta: Quantum Sinergis Media.

Imanti, Muthomimah, \& Setyowati, Maryani. (2015). Analisis Kebutuhan Tenaga Kerja Berdasakan Beban Kerja Unit Rekam Medis Rumah Sakit Islam Kendal Tahun 2015. Diakses Dari Http://Eprints. Dinus. Ac. Id/Id/Eprin, 17489.

Indradi, Rano. (2017). Rekam Medis (2nd ed.). Tangerang Selatan: Unversitas Terbuka.

Jacobis, Ghiok Vanali, Kojo, Christoffel, \& Wenas, Rudy S. (2017). Pengaruhh Karakteristik Individu Dan Lingkungan Kerja Terhadap Kinerja Pegawai Di Dinas Lingkungan Hidup Daerah Provinsi Sulawesi Utara. Jurnal EMBA: Jurnal Riset Ekonomi, Manajemen, Bisnis Dan Akuntansi, 5(2), 2015-2022. https://doi.org/10.35794/emba.v5i2.16485

Komisi Akreditasi Rumah Sakit. (2016). Dokumen Rekam Medis Dalam Konteks Akreditasi Rumah Sakit versi 2012 (1st ed.). Jakarta.

Masthuroh, Imas, \& Anggita, Nauri. (2018). Metedologi Penelitian kesehatan. Kementrian kesehatan Republik Indonesia.

Muhaemin, Muhaemin. (2017). Pengembangan Sistem Informasi Rencana Kebutuhan SDM Kesehatan dengan Metode Analisis Beban Kerja Studi Kasus: BPPSDMKKementerian Kesehatan. Jurnal Sains, Teknologi Dan Industri, 14(2), 219-224.

Notoamodjo Soekidjo. (2018). Metodologi Penelitian Kesehatan. Jakarta: PT. Rineka Cipta.

Permenkes, R. I. (2008). No 269/Menkes/Per/III/2008 tentang Rekam Medis. Jakarta: Menteri Kesehatan Reupublik Indonesia.

Permenkes RI. (2008). Permenkes RI 269/MENKES/PER/III/2008. Permenkes Ri No 269/Menkes/Per/Iii/2008, Vol. 2008, p. 7.

Tengah, Jawa, Tahun, Periode, \& Alifah, Fatimah. (2014). Analisis Beban Kerja Petugas Assembling Dengan Metode Wisn dI RSJD Dr. Amino gondohutomo provinsi.

Tim Pusrengun SDM Kesehatan PPSDM Kes RI Konsultan: Pardjono, SKM, MPH. (2017). Buku Manual 1 Perencanaan Kebutuhan SDM Kesehatan Berdasarkan Metode Analisis Beban Kerja Kesehatan ( ABK Kes ). In BPPSDM Kesehatan RI.

(C) 2021 by the authors. Submitted for possible open access publication under the

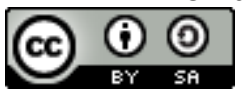
terms and conditions of the Creative Commons Attribution (CC BY SA) license (https://creativecommons.org/licenses/by-sa/4.0/). 